Journal acronym: GSPM

Author(s): $\quad$ Giuseppe Coratella, Marco Beato and Federico Schena

Article title: The specificity of the Loughborough Intermittent Shuttle Test for recreational soccer players is independent of their intermittent running ability

Article no: $\quad 1222279$

Enclosures: $\quad$ 1) Query sheet

2) Article proofs

Dear Author,

1. Please check these proofs carefully. It is the responsibility of the corresponding author to check these and approve or amend them. A second proof is not normally provided. Taylor \& Francis cannot be held responsible for uncorrected errors, even if introduced during the production process. Once your corrections have been added to the article, it will be considered ready for publication.

Please limit changes at this stage to the correction of errors. You should not make trivial changes, improve prose style, add new material, or delete existing material at this stage. You may be charged if your corrections are excessive (we would not expect corrections to exceed 30 changes).

For detailed guidance on how to check your proofs, please paste this address into a new browser window: http://journalauthors.tandf.co.uk/production/checkingproofs.asp

Your PDF proof file has been enabled so that you can comment on the proof directly using Adobe Acrobat. If you wish to do this, please save the file to your hard disk first. For further information on marking corrections using Acrobat, please paste this address into a new browser window: http://journalauthors.tandf.co.uk/production/acrobat.asp

2. Please review the table of contributors below and confirm that the first and last names are structured correctly and that the authors are listed in the correct order of contribution. This check is to ensure that your name will appear correctly online and when the article is indexed.

\begin{tabular}{|l|l|l|l|l|}
\hline Sequence & Prefix & Given name(s) & Surname & Suffix \\
\hline 1 & & Giuseppe & Coratella & \\
\hline 2 & & Marco & Beato & \\
\hline 3 & & Federico & Schena & \\
\hline
\end{tabular}


Queries are marked in the margins of the proofs, and you can also click the hyperlinks below.

Content changes made during copy-editing are shown as tracked changes. Inserted text is in red font and revisions have a red indicator $\curlywedge$. Changes can also be viewed using the list comments function. To correct the proofs, you should insert or delete text following the instructions below, but do not add comments to the existing tracked changes.

\section{General points:}

\section{AUTHOR QUERIES}

1. Permissions: You have warranted that you have secured the necessary written permission from the appropriate copyright owner for the reproduction of any text, illustration, or other material in your article. Please see http://journalauthors.tandf.co.uk/permissions/usingThirdPartyMaterial.asp.

2. Third-party content: If there is third-party content in your article, please check that the rightsholder details for re-use are shown correctly.

3. Affiliation: The corresponding author is responsible for ensuring that address and email details are correct for all the co-authors. Affiliations given in the article should be the affiliation at the time the research was conducted. Please see http://journalauthors.tandf.co.uk/preparation/writing.asp.

4. Funding: Was your research for this article funded by a funding agency? If so, please insert 'This work was supported by <insert the name of the funding agency in full>', followed by the grant number in square brackets '[grant number xxxx]'.

5. Supplemental data and underlying research materials: Do you wish to include the location of the underlying research materials (e.g. data, samples or models) for your article? If so, please insert this sentence before the reference section: 'The underlying research materials for this article can be accessed at $<$ full link> / description of location [author to complete]'. If your article includes supplemental data, the link will also be provided in this paragraph. See <http://journalauthors.tandf.co.uk/preparation/multimedia.asp $>$ for further explanation of supplemental data and underlying research materials.

6. The CrossRef database (www.crossref.org/) has been used to validate the references. Changes resulting from mismatches are tracked in red font.

AQ1 please check wheather the article title is set correctly.

AQ2 The CrossRef database (www.crossref.org/) has been used to validate the references. Mismatches between the original manuscript and CrossRef are tracked in red font. Please provide a revision if the change is incorrect. Do not comment on correct changes. 


\section{How to make corrections to your proofs using Adobe Acrobat/Reader}

Taylor \& Francis offers you a choice of options to help you make corrections to your proofs. Your PDF proof file has been enabled so that you can mark up the proof directly using Adobe Acrobat/Reader. This is the simplest and best way for you to ensure that your corrections will be incorporated. If you wish to do this, please follow these instructions:

1. Save the file to your hard disk.

2. Check which version of Adobe Acrobat/Reader you have on your computer. You can do this by clicking on the "Help" tab, and then "About".

If Adobe Reader is not installed, you can get the latest version free from http://get. adobe.com/reader/.

3. If you have Adobe Acrobat/Reader 10 or a later version, click on the "Comment" link at the right-hand side to view the Comments pane.

4. You can then select any text and mark it up for deletion or replacement, or insert new text as needed. Please note that these will clearly be displayed in the Comments pane and secondary annotation is not needed to draw attention to your corrections. If you need to include new sections of text, it is also possible to add a comment to the proofs. To do this, use the Sticky Note tool in the task bar. Please also see our FAQs here: http://journalauthors.tandf.co.uk/production/index.asp.

5. Make sure that you save the file when you close the document before uploading it to CATS using the "Upload File" button on the online correction form. If you have more than one file, please zip them together and then upload the zip file.

If you prefer, you can make your corrections using the CATS online correction form.

\section{Troubleshooting}

Acrobat help: http://helpx.adobe.com/acrobat.html

Reader help: http://helpx.adobe.com/reader.html

Please note that full user guides for earlier versions of these programs are available from the Adobe Help pages by clicking on the link "Previous versions" under the "Help and tutorials" heading from the relevant link above. Commenting functionality is available from Adobe Reader 8.0 onwards and from Adobe Acrobat 7.0 onwards.

Firefox users: Firefox's inbuilt PDF Viewer is set to the default; please see the following for instructions on how to use this and download the PDF to your hard drive: http://support.mozilla.org/en-US/kb/view-pdf-files-firefox-without-downloadingthem\#w_using-a-pdf-reader-plugin 


\title{
The specificity of the Loughborough Intermittent Shuttle Test for recreational soccer players is independent of their intermittent running ability
}

\author{
Giuseppe Coratella ${ }^{\mathrm{a}}$, Marco Beato ${ }^{\mathrm{a}, \mathrm{b}}$ and Federico Schena ${ }^{\mathrm{a}}$
}

aDepartment of Neurological, Biomedical and Movement Science, University of Verona, Verona, Italy;

${ }^{\mathrm{b}}$ Faculty of Health and Science, Department of Science and Technology, University of Suffolk, Ipswich, UK

\begin{abstract}
The aim of the present study was to evaluate whether or not recreational soccer players (SP) and non-soccer players (non-SP) with similar intermittent-running ability had similar physiological responses to a soccer match-simulation protocol. Twenty-two recreational SP and 19. fitness-matched non-SP participated. YoYo level 1 assessed intermittent-running ability, while the Loughborough Intermittent Shuttle Test served as soccer matchsimulation protocol. Heart rate (HR), blood lactate concentration $\left[\mathrm{La}^{-}\right]$and rating of perceived exertion (RPE) were recorded after each bout (1 $1-5$, plus an exhaustive task). SP had lower HR after the third, fourth and fifth bout, compared to non-SP. Similarly, SP had lower [ $\left.\mathrm{La}^{-}\right]$after the third, fourth and the fifth bout. SP also had lower RPE after the third, fourth and fifth bout. The appropriateness of intermittent-running ability as the main determinant of physical performance in SP was questioned.
\end{abstract}

\section{ARTICLE HISTORY}

Received 17 April 2016

Accepted 21 July 2016

\section{KEYWORDS}

Intermittent recovery test level 1; rating of perceived exertion; shuttle running; repeated-sprint ability; soccer match simulation

\section{Introduction}

Soccer is characterized by an intermittent-activity profile with metabolic contributions from both the aerobic and anaerobic systems. Soccer players (SP) cover distances of $10-13 \mathrm{~km}$ during matches_and perform approximately 1350 activities, with variations every 4-6 s (Mohr, Krustrup, \& Bangsbo, 2005). In addition to technical skills, physical abilities such as intermittent-running and repeated-sprint ability (RSA) are key factors during competition. Indeed, the physical demands of competition have increased in recent years (Bush, Barnes, Archer, Hogg, \& Bradley, 2015) particularly in regards to highintensity activities (Barnes, Archer, Hogg, Bush, \& Bradley, 2014). Therefore, it is important for soccer practitioners to identify simple tests than can be used to evaluate physical capabilities that contribute to overall performance (Impellizzeri, Rampinini, \& Marcora, 2007). Such tests can be used to monitor training adaptations, identify the current status of a playen and for talent identification and selection purposes. Physical capabilities of $\mathcal{S P}_{\mathrm{S}}$ are often difficult to assess in isolation (Paul, Bradley, \& Nassis, 2015). Notwithstanding, several testing assessments have been validated for evaluating the

CONTACT Giuseppe Coratella giuseppe.coratella@univr.it $\Theta$ Department of Neurological and Movement Science, University of Verona, via Casorati 43, 37131 Verona, Italy

(c) 2016 Informa UK Limited, trading as Taylor \& Francis Group 
main soccer physical determinants. Both laboratory-based or field-based procedures can be used for measuring the aerobic characteristics (Manzi, Impellizzeri, \& Castagna, 2014), the RSA (Ferrari Bravo et al., 2008), or the intermittent-running ability. Importantly, the latter has been widely proposed as the main $S P$ determinant (Bangsbo, 1994). Therefore, several testing protocols have been created for ensuring accuracy and reliability, such as the Yo-Yo intermittent recovery test (Krustrup et al., 2003), the 30-15 intermittent fitness test (Buchheit, 2008) and Carminatti's test (Teixeira et al., 2014).

The Yo-Yo intermittent recovery test level 1 (IR1) is a generally accepted test of physical fitness in soccer and other team sports. It is reliable (Krustrup et al., 2003) and discriminates between competitive standard and playing position (Mohr \& Krustrup, 2014), making the test useful for talent selection purposes. It has been suggested that the IR1 can be used as a comprehensive test to reflect soccer-specific fitness (Ingebrigtsen et al., 2014). Many practitioners and researchers rely on IR1 performance to infer on a player's physical condition, mainly because the test scores are related to match running performance (Krustrup et al., 2003). However, the validity of IR1 as a comprehensive evaluation of specific soccer performance was questioned early in the development of the test (Kindermann \& Meyer, 2003). IR1 performance is a compound quality, which depends on multiple physical fitness factors (Mendez-Villanueva \& Buchheit, 2013). This is an indication that using a single physical capacity test (e.g. intermittent-running ability measured by IR1) as a proxy for soccer-specific fitness might be misrepresenting the actual demands of matches.

A different approach to the evaluation of soccer-specific fitness is to measure performance, physiological and perceptual responses to match-simulation protocols. Two main protocols have been used in applied research settings: the Loughborough Intermittent Shuttle Test (LIST; Thompson, Nicholas, \& Williams, 1999), and the Football-specific Aerobic Field Test (Small, McNaughton, Greig, Lohkamp, \& Lovell, 2009). These tests are based on the repetition of alternated types of locomotion (e.g. sprinting, running, walking) for a total duration of $90 \mathrm{~min}$. The LIST has received more attention in recent years, for example to investigate effects of fatigue on muscle imbalance (Coratella, Bellin, Beato, \& Schena, 2015), and it was therefore selected for the present investigation. Moreover, the test displays acceptable reliability (Nicholas, Nuttall, \& Williams, 2000) and it has been recently modified to improve its reflection of modern football demands (Ali, Foskett, \& Gant, 2014). Finally, the LIST had similar responses for muscle damage markers and neuromuscular variables compared to a soccer match (Magalhães et al., 2010).

While LIST is commonly used as a soccer-specific fitness assessment tool, there is limited information about its ecological or discriminant validity (i.e, time to exhaustion and physiological responses). In addition, as the LIST protocol depends on the intermittent-running ability (which can be measured by IR1), a positive relationship between the two should occur. Indeed, two out of the foun actions performed in the LIST directly derived from the IR1. It can be expected that, given the predominance of the intermittent-running ability among the soccer-specific physical capacities, increasing such capacity can lead to better physiological responses during a soccer match-simulation protocol, as already shown for soccer matches (Krustrup et al., 2003). On the contrary, similar intermittent-running ability should lead to similar physiological responses.

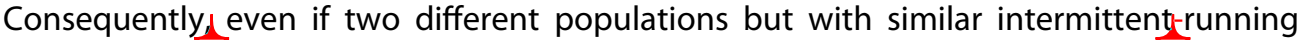


abilities should perform the LIST, similar physiological responses should result. To date, no study has investigated the responses to LIST in two different groups (SP and nonsoccer players [non-SP]) with a similar intermittent-running ability. Therefore, the aim of the present study was to investigate whether or not LIST discriminates between recreational $S P$ and non- $S P$, and whether this would be dependent on intermittent-running ability.

\section{Methods}

\section{Experimental approach to the problem}

This study was conducted as a parallel two-group design. An a-priori power analysis was performed (two-tail, effect size [ES] $=0.5$ _[medium], alpha-error $=0.05$ and power $=0.80$ ) and it returned a desired sample size of 21 participants per group.

Forty-eight healthy male sport science students were initially recruited for the present study. Participants were involved in two separate testing sessions. The first session comprised an assessment of their intermittent-running ability (IR1). After the IR1 assessment, the intermittent-running ability of both soccer and non-SP was evaluated and compared and the maximal aerobic speed (MAS) was calculated (Bangsbo, laia, \& Krustrup, 2008). Then, from the initial pool of 26 non- $S P$, those with a comparable intermittent-running ability to the $S P$ were included in the present investigation. Therefore, as control group, 19 non-SP were finally included in the present study. In the second session, the participants completed the standardized football match-simulation protocol (LIST). During this session, heart rate (HR), rating of perceived exertion (RPE) and blood lactate concentration were assessed. The two testing sessions were separated by $1_{\Lambda}$ week. Participants were instructed to refrain from any form of strenuous physical activity for the entire duration of the study.

\section{Participants}

Twenty-two SP (age 20.1 \pm 2.4 years, height $1.77 \pm 0.09 \mathrm{~m}$, body mass $78.3 \pm 2.8 \mathrm{~kg}$ ), with at least 5 years of soccer experience, and 19 non-SP (age $20.3 \pm 1.9$ years, height $1.79 \pm 0.10 \mathrm{~m}$, weight $79.7 \pm 3.7 \mathrm{~kg}$ ) were recruited for this project. Non-SP were enrolled among different sports: six recreational basketball players, five three recreational futsal players, three recreational triathlon athletes, two recreational tennis players. Participants with cardiovascular or respiratory diseases as well as knee, ankle or hip joint injury were excluded from participation. All participants were previously informed about the benefits and risks associated with the procedures, and they provided a written consent to participate in the project, which was approved by the Ethics Committee of the University of Verona.

\section{Procedures}

Yo-Yo $\ R 1$

This test comprised $2 \lambda \times 20-\mathrm{m}$ shuttle runs at increasing speeds, separated by $10 \mathrm{~s}$ of active recovery (Krustrup et al., 2003). The participants were required to run on a 
parquet-floor indoor court, guided by an audio signal, until they were unable to maintain the desired speed. The test was ended when participants were no longer able to reach the finish line on the signal for two consecutive occasions. The stage reached and total distance covered $\left(\mathrm{m}\right.$ ) were recorded. The $\mathrm{VO}_{2}$ peak and $\mathrm{MAS}$ 玲 were calculated according to Bangsbo et al. (2008).

LIST/

The LIST protocol was divided in two parts. The first part comprised five bouts in which participants sprinted, walked and ran at 55\% and 95\% of the MAS, on a 20-m shuttle track. Specifically, participants had to

- walk $3 \times 20 \mathrm{~m}$ <

- sprint $1 \times 20 \mathrm{~m}_{\text {ג }}$

- recover for 4 s.

- run at $55 \%$ of MAS $3 \times 20 \mathrm{~m}$.

- run at $95 \%$ of MAS $3 \times 20 \mathrm{~m}$.

This pattern was repeated for $15 \mathrm{~min}$ and each bout was separated by 3 min of recovery. The second part comprised 20-m shuttle running with alternated running at 55\% MAS and $95 \%$ of MAS, until exhaustion. Operators encouraged the participants to maintain the audio signal pace while running. The test ended when participants failed to run two consecutive $20 \mathrm{~m}$ shuttles in their own pre-established pace. Time to exhaustion was recorded.

\section{Physiological responses}

$\mathrm{HR}$ Lwas recorded during the protocol using a standard HR monitor (Polar S810, Kempele, Finland) placed around the participants' upper thorax at the level of the xiphoid process. HR was recorded for the entire period of each bout and the exhaustive task. Then, the mean was analysed and inserted into the data analysis (Nicholas et al., 2000).

Blood lactate concentration [ $\mathrm{La}^{-}$] was assessed at baseline, immediately after the end of each bout, and after the exhaustive task. Blood samples were collected using capillary blood from an ear lobe. Then, the blood samples were immediately placed onto a sample strip and inserted into a hand-held lactate analyser (EKF Diagnostic GmbH, Magdeburg, Germany) for single measurements.

RPE was assessed using a 6-20 scale (Borg, 1982). Participants were carefully instructed about the purpose of the scale and accustomed to the procedures. Standard anchoring was performed by asking the participants to associate a previous experience of a light walking exercise to a rating of 7, and a near maximal running bout to a rating of 19. RPE was assessed after the end of each bout and after the exhaustive task.

\section{Statistical analysis}

Data analysis was performed using SPSS 16.0 (SPSS, Chicago, IL). The normality of data was investigated using the Shapiro-Wilk's test. The sphericity of data was investigated using the Mauchly's test. The HR RPE and blood lactate concentration 
between groups were compared using a mixed-design factorial ANOVA. Post-hoQ analysis using Bonferroni's correction was executed to investigate the effect for group (two groups: SP and non-SP) and time (seven levels in $\left[\mathrm{La}^{-}\right]$and in HR and six levels in RPE). The estimated $\mathrm{VO}_{2}$ peak, MAS and time to exhaustion between SP and non-SP were compared using a between-groups one-way ANOVA. Data are reported as mean \pm SD. Post-hog comparisons are shown as mean difference \pm SD with absolute change score (CI95\%) and Cohen's standardized ES, with $95 \%$ confidence limits $(\mathrm{CL})$. ES was classified as follows: $\geq 0.2$ small, $\geq 0.5$ moderate and $\geq 0.8$ large.

\section{Results}

\section{IR1 performance}

There was no difference in the IR1 performance between SP and non-SP, being $1476 \pm 344$ and $1406 \pm 486 \mathrm{~m}$, respectively. Therefore, MAS was similar between the two groups (13.9 \pm 0.8 and $13.8 \pm 1.2 \mathrm{~km} \mathrm{~h}^{-1}$ for SP and non-SP/respectively).

\section{LIST time to exhaustion}

The time to exhaustion in part B of LIST was longer in SP than in non-SP $(313.2 \pm 48.2$ and $220.1 \pm 51.2 \mathrm{~s}$, respectively, $\underline{p}=0.002$, ES $=1.97, C L$ 1.43-2.51).

\section{LHR}

Main effect for group was found for HR during LIST $\left(p_{\alpha}=0.039\right)$. Compared to non-SP, SP showed moderately lower HR after bout $3\left(-9.0 \pm 4.4 b_{\lambda} \min ^{-1}\right.$. Cl95\% -17.8 to $\left.-0.1, p_{2}=0.048, E S=0.61, C L \quad 0.01-1.22\right)$, after bout $4\left(-8.7 \pm 3.9 b_{2} \min ^{-1}, C 195 \%-16.8\right.$ to $-0.6, p_{\lambda}=0.035$, ES $\left.=0.65, C L \quad 0.05-1.26\right)$ and mostly lower after bout 5 $\left(-11.9 \pm 3.8 b_{\lambda} \min ^{-1}, C 195 \%-19.6\right.$ to $-4.3, p_{\lambda}=0.003, E S=0.89, C L$ 0.32-1.46) (Figure 1). Similarly, main effect for time was found $\left(p_{\lambda}<0.001\right)$. Compared to baseline, post-hog analysis showed HR increments over time after each bout and after the exhaustive task for both SP and non-SP $\left(p_{\alpha}<0.05\right)$. Finally, A time $\times$ group interaction was found $\left(p_{2}=0.041\right)$.

\section{Blood lactate concentration}

Main effect for group was found for $\left[\mathrm{La}^{-}\right]$during LIST $(\underline{\underline{\alpha}}=0.028)$. Compared to non-SP, SP had moderately lower [ $\left.\mathrm{La}^{-}\right]$after bout $3\left(-0.8 \pm 0.4 \mathrm{mmol} \mathrm{L}^{-1}, \mathrm{Cl} 95 \%-1.4\right.$ to -0.2 , $\underline{Q}=0.041, E S=0.59, C L 0.05-1.13)$ and after bout $4\left(-1.0 \pm 0.5 \mathrm{mmol}_{\mathbf{L}} \mathrm{L}^{-1}, \mathrm{Cl} 95 \%-1.6\right.$ to $-0.4, \underline{Q}=0.027, \mathrm{ES}=0.74, \mathrm{CL}$ 0.19-1.29) and mostly lower after bout 5 $\left(-1.0 \pm 0.5 \mathrm{mmol}^{-1} \mathrm{~L}^{-1},-1.6\right.$ to $-0.4, \underline{\underline{\lambda}}=0.010, \mathrm{ES}=0.81, \mathrm{CL} 0.30-1.32$ ) (Figure 2). Similarly, main effect for time was found $(\underline{2}<0.001)$. Compared to baseline, post-hoQ analysis showed greater $\left[\mathrm{La}^{-}\right]$over time after each bout and after the exhaustive task both for SP and non-SP $\left(p_{\alpha}<0.05\right)$. Finally, time $\times$ group interaction was found $(p=0.031)$. 


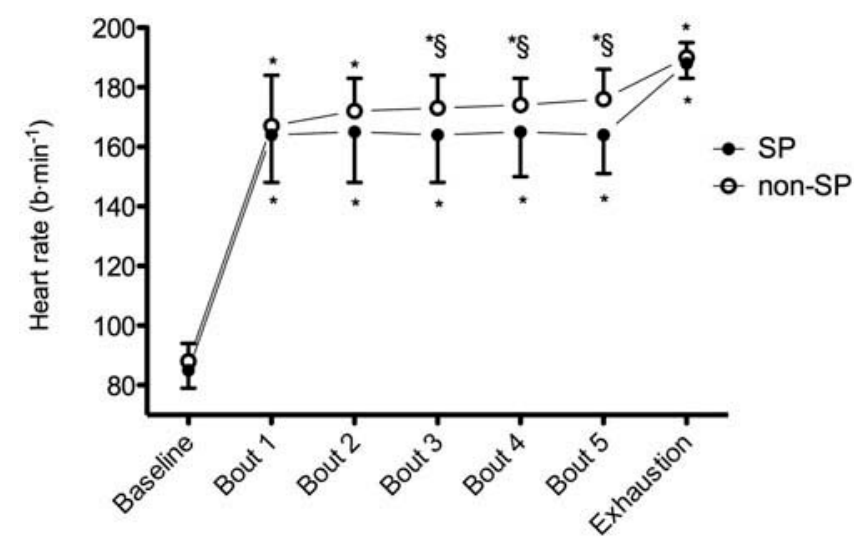

Figure 1. Difference in heart rate between SP and non-SP after each bout and at exhaustion. Data are shown as mean \pm SD. ${ }^{*}$ Q $<<0.05$ compared to baseline ${ }^{\S} \rho_{2}<0.05$ compared to SP.

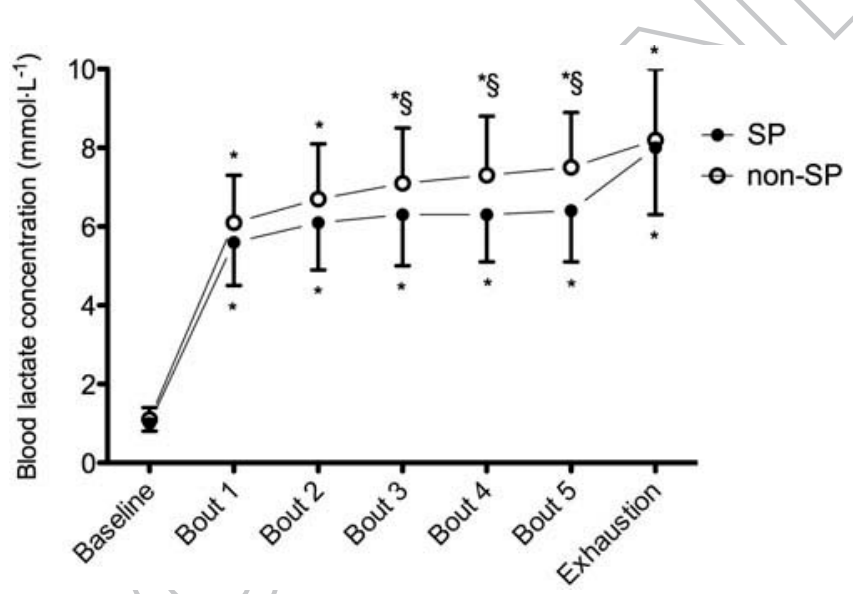

Figure 2. Difference in blood lactate accumulation between SP and non-SP after each bout and at exhaustion. Data are shown as mean \pm SD. ${ }^{*} g<0.05$ compared to baseline ${ }^{\aleph_{j}} g<<0.05$ compared to SP.

\section{RPE}

Main effect for group was found for RPE during LIST ( $p=0.004)$. Compared to non-SP, SP showed moderately lower RPE after bout $2\left(-1.4 \pm 0.5 \mathrm{~A}_{\mathrm{k}} \mathrm{Cl}\right.$ (95\% $\%-2.5$ to $-0.3, p_{\mathrm{L}}=0.011,200$ $\mathrm{ES}=0.78, \mathrm{CL} 0.19-1.37)$ and after bout $4\left(-1.5 \pm 0.6 \mathrm{AU}_{\alpha} \mathrm{Cl} 195 \%-2.7\right.$ to $-0.3, p_{2}=0.015$, $\mathrm{ES}=0.75, \mathrm{CL} 0.15-1.34)$, while the RPE was mostly lower after bout $3(-1.9 \pm 0.6 \mathrm{~A}$ k $\mathrm{Cl} 195 \%-3.0$ to $\left.-0.7, p_{2}=0.002, \mathrm{ES}=0.92, \mathrm{CL} 0.36-1.49\right)$ and after bout $5\left(-1.9 \pm 0.6 \mathrm{AU}_{\text {k }}\right.$ $\mathrm{Cl} 195 \%-3.0$ to $-0.6, p_{\alpha}=0.004, \mathrm{ES}=0.87, \mathrm{CL} 0.30-1.45$ ) (Figure 3). Similarly, main effect for time was found $\left(p_{2}<0.001\right)$. Compared to exhaustion, post-hog analysis revealed lower values over time after each bout both for SP and non-SP $\left(p_{\alpha}<0.05\right)$. Finally, time $\times$ group interaction was found $\left(p_{2}=0.018\right)$. 


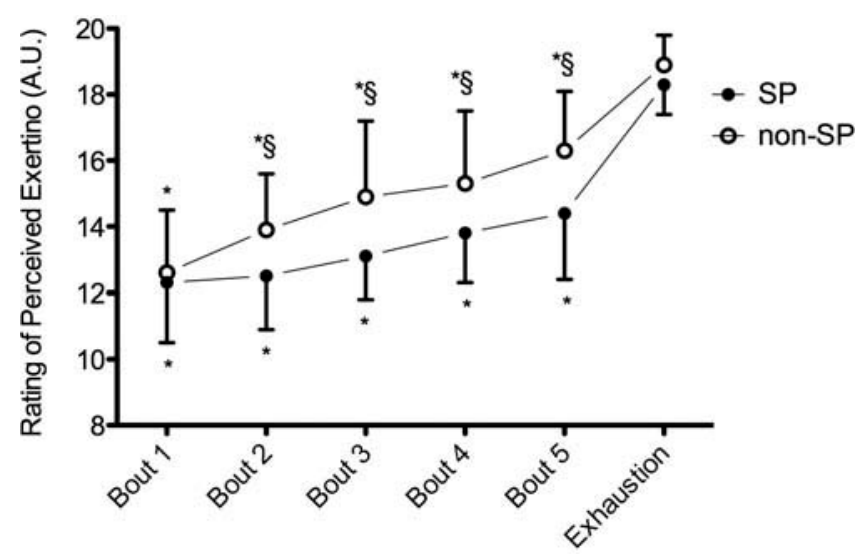

Figure 3. Difference in rating of perceived exertion between SP and non-SP after each bout and at

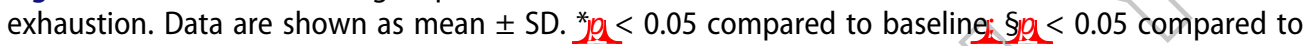
SP.

\section{Discussion}

The present study was designed to investigate whether or not SP and non-SP with similar intermittent-running ability had similar physiological responses to a standardized soccer match simulation. The present results showed lower/HR, blood lactate concentration and RPE in SP compared to non-SP during the sub-maximal component of LIST. In addition, SP reached exhaustion later compared to non-SP.

Soccer has previously been defined as an aerobic task with a large component of intermittent exercise (Bangsbo, 1994). Subsequently, practitioners and researchers have focused their attention on the effect of intermittent exercise (or high-intensity interval training) on physiological adaptations and players' performance. Indeed, maintaining exercise intensity close to $\mathrm{VO}_{2}$ peak is well known to induce both cardiovascular and pulmonary adaptations (Buchheit \& Laursen, 2013a). In addition, neuromuscular adaptations such as improvements in muscle fibre recruitment and consequently greater strength development, as well as increases in resistance to fatigue are induced by intermittent exercise (Buchheit \& Laursen, 2013b). Importantly, intermittent exercise increased the blood lactate clearance (Ahmaidi et al., 1996). Finally, intermittent-exercise training performed both in traditional (e.g, running) and in soccer-specific (e.g, small side games) modalities was equally effective for promoting aerobic fitness and match performance (Impellizzeri et al., 2006). Therefore, it seems that increasing the players' intermittent-running ability can provide useful adaptations for improving the soccer performance. Such a relationship has been previously showed in young (Castagna, Impellizzeri, Cecchini, Rampinini, \& Alvarez, 2009) and professional adult SP (Bangsbo \& Lindquist, 1992).

Among the field tests measuring the intermittent-running ability, the IR1 is perhaps the most used. It was demonstrated to be valid and reliable (Krustrup et al., 2003), as well as soccer-specific (Castagna, Impellizzeri, Chamari, Carlomagno, \& Rampinini, 2006). Indeed, IR1 is able to discriminate between different competitive levels (Bangsbo et al., 2008). In addition, IR1 can be successfully used to monitor training responsiveness in 


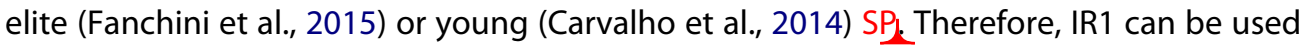
for evaluating the players' intermittent-running ability.

The variety of soccer actions cannot be reduced only to a simple intermittent-exercise task. Several studies have investigated soccer match performance by match analysis and they showed that both non-technical and non-tactical tasks such as standing, walking, jogging, running or sprinting have been identified within soccer matches (Sarmento et al., 2014). For example, soccer matches include several brief sprints, interspersed with short recoveries (Padulo et al., 2015). The ability to limit decrements in repeated-sprint performance has been termed RSA (Girard, Mendez-Villanueva, \& Bishop, 2011). Even if the amount of sprints performed during the soccer matches depends on the players role, age and playing time (Buchheit, Mendez-villanueva, Simpson, \& Bourdon, 2010), RSA has been identified as one of the key factors in soccer match performance (Spencer, Bishop, Dawson, \& Goodman, 2005). Several factors contribute to RSA, such as PCr availability, oxidative phosphorylation, anaerobic glycolysis and buffer capacity (Girard et al., 2011). Previous studies have reported positive correlations between RSA and aerobic fitness in SP (Da Silva, Guglielmo, \& Bishop, 2010), and RSA was impaired by fatigue irrespective of the players role (Kaplan, 2010). Subsequently, several training protocols have been recommended for improving RSA in SP (Bishop, Girard, \& MendezVillanueva, 2011). Therefore, the $S_{P_{\curlywedge}}$ involved in the present study may have more efficiently managed the sprint-induced fatigue than non-SP.

LIST is performed on a 20-m shuttle run course, in order to mimic the several changes of direction (COD) in which $\mathrm{SP}_{\curlywedge}$ are involved during a match. Although the inclusion of COD into the intermittent exercise did not modify the metabolic response and the RPE, the lowen limb muscle activity was affected by COD compared to straight-only intermittent exercise (Hader, Mendez-Villanueva, Ahmaidi, Williams, \& Buchheit, 2014). Quadriceps, hamstrings and gastrocnemii activity resulted greater when COD is included into the intermittent exercise, mainly due to the increasing knee stabilization (Besier, Lloyd, \& Ackland, 2003). Such increased muscular activity could be related to the twofold (or even more) energy cost of shuttle runs compared to straight run, as recently shown (Buglione \& Di Prampero, 2013). In addition, while slightly more than one half of non-SP were confident with $C O D$, the remaining ones were habituated to linear movement patterns. Even if the IR1 does include the COD in its protocol, the duration of the LIST (and soccer match) is greatly longer than IR1. Furthermore, the inclusion of COD in training can help to manage fatigue from both a psychological and metabolic points of view (Hader et al., 2014). Therefore, considering the overall sports' backgrounds of the two selected populations, it is likely that SP can be more conditioned to COD than non-SP.

While no difference in physiological responses was found comparing SP and non-SP at the end of LIST, SP reached exhaustion mostly later than non-SP. In addition, after the third, fourth and fifth bout of LIST (i.e, after 51, 69 and 87 min, respectively), HR, blood lactate concentration and RPE were moderately or mostly lower in SP than non-SP. During the 90+ minutes of a soccer match, players experience several periods of temporary fatigue, particularly in the initial phase of the second period, and at the end of the match (Mohr et al., 2005). The fatigue perceived during a match can derive from both metabolic and psychobiological factors (Paul et al., 2015). The same authors suggested that SP could establish a self-selected pacing, voluntary or subconscious, which insulates them from both 
metabolic and mental fatigue (Paul et al., 2015). It may be speculated that SP better manage the fatiguing process during LIST compared to non-SP.

Considering the pooled data, HR increased from the baseline after each bout until exhaustion in both groups. The present results are in line with previous studies that monitored the $\mathrm{HR}_{\mathcal{Q}}$ during LIST both in recreational or semi-professional SP (Magalhães et al., 2010; Nicholas et al., 2000) and in students who were active in other sports (Thompson et al., 1999). [ $\mathrm{La}^{-}$] increased from the baseline after each bout until the exhaustion in both groups, in line with previous studies that measured [ $\left.\mathrm{La}^{-}\right]$during LIST in recreational SP(Nicholas et al., 2000). However, non-SP resulted in higher [ $\mathrm{La}^{-}$] compared to previous studies. Such a difference could be explained by a greater aerobic fitness level $\left(55 \pm 1\right.$ vs. $48 \pm 4 \mathrm{~mL} \mathrm{~min}^{-1} \mathrm{~kg}^{-1}$ ) of the participants involved in the previous study (Thompson et al., 1999) compared to those enrolled in the present investigation. RPE is a valid and reliable method introduced for monitoring the perception of effort during an exercise session (Borg, 1982). In addition, the RPE recorded during interval and team sport sessions is a useful method for evaluating the intensity of the training load (Foster et al., 2001). The RPE recorded in SP is in line with a previous study in which recreational male $S_{\curlywedge}$ were recruited (Delextrat, Gregory, \& Cohen, 2010). Unfortunately, no suitable comparison regarding non-SP was found. Finally, both SP and non-SP experienced similar RPE immediately after the exhaustive task, possibly meaning that both groups experienced an effort close their maximal when they reached exhaustion (Marcora \& Staiano, 2010).

The present study comes with some acknowledged limitations and also interesting perspectives for future research. First, the population recruited for this study comprised $_{\alpha}$

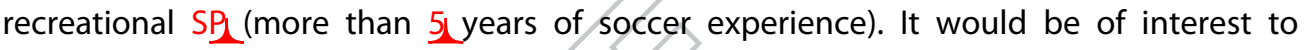
design similar investigations including semi-professional or professional players. It may be speculated that differences in physiological parameters could be even greater, but this remains to be proved. Similarly, LIST could be useful to discriminate SP among different levels. Second, LIST was used for simulating a soccer match and although LIST has been widely used in literature for this purpose, performing modified versions of LIST, (Ali et al., 2014), or different soccer match-simulations protocols (Small et al., 2009), could have different impacts on the resulting physiological parameters. Finally, we have no data in regards to specific differences in sprinting activities between SP and non-SP. Although each participant maximally performed each sprint, it could have been useful to analyse differences in sprinting performances over the entire duration of the LIST.

In conclusion, lower $\mathrm{HR},\left[\mathrm{La}^{-}\right]$and RPE were found in recreational SP compared to non-SP matched for intermittent-running ability when performing the first part of LIST. In addition, SP performed the exhausting task longer than non-SP. The intermittentrunning ability, although important for soccer match performance, could not entirely describe the physical demands in a soccer match simulation. $\mathrm{RSA}_{\alpha}$ change of direction and specific-task fatigue management should be taken into account for more accurately describing the physiological profile of the recreational $\mathrm{SP}_{\text {<. }}$

\section{Practical applications}

The IR1 has been largely used for measuring the intermittent-running ability of $\mathrm{SP}_{\mathcal{L}}$. However, the present study questioned the suitability of intermittent-running ability as the main physical ability in recreational $\mathrm{SP}_{\curlywedge}$ Although the IR1 is easy to prescribe, it 
should not be considered as a comprehensive test for such specific population. Therefore, in order to have a more comprehensive evaluation, it is recommended that intermittent-running ability should be assessed in conjunction with other specific tests, for example RSA and COD agility tests.

On the other hand, the present investigation suggests that soccer-specific, traininginduced adaptations can be highlighted in recreational $\mathrm{SP}_{\mathcal{\lambda}}$ by performing a match simulation. Therefore, LIST can be successfully used for both cross-sectional and longitudinal task-specific physiological evaluations in recreational $\mathrm{SP}_{\text {感 }}$

\section{Acknowledgements}

The authors wanted to thank Giuseppe Bellin, B.Sc., Alessandro Pacifici, M.Sc., Giulia Visentin, M.Sc., for their precious help in data collection. Authors are grateful to all the participants that volunteered to this study.

\section{Disclosure statement}

The authors stated that they have no conflict of interests,

\section{Funding}

The present work received no fund.

\section{References}

Ahmaidi, S., Granier, P., Taoutaou, Z., Mercier, J., Dubouchaud, H., \& Prefaut, C. (1996). Effects of active recovery on plasma lactate and anaerobic power following repeated intensive exercise. Medicine and Science in Sports and Exercise, 28(4), 450-456.

Ali, A., Foskett, A., \& Gant, N. (2014). Measuring intermittent exercise performance using shuttle running. Journal of Sports Sciences, 32(7), 601-609. doi:10.1080/02640414.2013.847276

Bangsbo, J. (1994). The physiology of soccer-with special reference to intense intermittent exercise. Acta Physiologica Scandinavica. Supplementum, 619, 1-155.

Bangsbo, J., laia, F. M., \& Krustrup, P. (2008). The Yo-Yo intermittent recovery test: A useful tool for evaluation of physical performance in intermittent sports. Sports Medicine (Auckland, N.Z.), 38(1), 37-51.

Bangsbo, J., \& Lindquist, F. (1992). Comparison of various exercise tests with endurance performance during soccer in professional players. International Journal of Sports Medicine, 13(2), 125132. doi:10.1055/s-2007-1021243

Barnes, C., Archer, D. T., Hogg, B., Bush, M., \& Bradley, P. S. (2014). The evolution of physical and technical performance parameters in the English premier league. International Journal of Sports Medicine, 35(13), 1095-1100. doi:10.1055/s-0034-1375695

Besier, T. F., Lloyd, D. G., \& Ackland, T. R. (2003). Muscle activation strategies at the knee during running and cutting maneuvers. Medicine and Science in Sports and Exercise, 35(1), 119-127. doi;10.1097/00005768-200301000-00019

Bishop, D., Girard, O., \& Mendez-Villanueva, A. (2011). Repeated-sprint ability part II: Recommendations for training. Sports Medicine, 41(9), 741-756. doi:10.2165/11590560000000000-00000

Borg, G. A. (1982). Psychophysical bases of perceived exertion. Medicine and Science in Sports and 365 Exercise, 14(5), 377-381. 
Buchheit, M. (2008). The 30-15 intermittent fitness test: Accuracy for individualizing interval training of young intermittent sport players. Journal of Strength and Conditioning Research, 22 (2), 365-374. doi:10.1519/JSC.0b013e3181635b2e

Buchheit, M., \& Laursen, P. B. (2013a). High-intensity interval training, solutions to the programming puzzle: Part I: Cardiopulmonary emphasis. Sports Medicine, 43(5), 313-338. doi:10.1007/ s40279-013-0029-x

Buchheit, M., \& Laursen, P. B. (2013b). High-intensity interval training, solutions to the programming puzzle: Part II: Anaerobic energy, neuromuscular load and practical applications. Sports Medicine, 43(10), 927-954. doi:10.1007/s40279-013-0066-5

Buchheit, M., Mendez-villanueva, A., Simpson, B. M., \& Bourdon, P. C. (2010). Repeated-sprint sequences during youth soccer matches. International Journal of Sports Medicine, 31(10), 709716. doi:10.1055/s-0030-1261897

Buglione, A., \& Di Prampero, P. E. (2013). The energy cost of shuttle running. European Journal of Applied Physiology, 113(6), 1535-1543. doi:10.1007/s00421-012-2580-9

Bush, M., Barnes, C., Archer, D. T., Hogg, B., \& Bradley, P. S. (2015). Evolution of match performance parameters for various playing positions in the English Premier League. Human Movement Science, 39, 1-11. doi:10.1016/j.humov.2014.10.003

Carvalho, H. M., Bidaurrazaga-Letona, I., Lekue, J. A., Amado, M., Figueiredo, A. J., \& Gil, S. M. (2014). Physical growth and changes in intermittent endurance run performance in young male Basque soccer players. Research in Sports Medicine, 22(4), 408-424. doi:10.1080/15438627.2014.944301

Castagna, C., Impellizzeri, F., Cecchini, E., Rampinini, E., \& Alvarez, J. C. B. (2009). Effects of intermittent-endurance fitness on match performance in young male soccer players. Journal of Strength and Conditioning Research, 23(7), 1954-1959. doi:10.1519/JSC.0b013e3181b7f743

Castagna, C., Impellizzeri, F. M., Chamari, K., Carlomagno, D., \& Rampinini, E. (2006). Aerobic fitness and yo-yo continuous and intermittent tests performances in soccer players: A correlation study. Journal of Strength and Conditioning Research, 20(2), 320-325. doi:10.1519/R-18065.1

Coratella, G., Bellin, G., Beato, M., \& Schena, F. (2015). Fatigue affects peak joint torque angle in hamstrings but not in quadriceps. Journal of Sports Sciences, 33(12), 1276-1282. doi:10.1080/ 02640414.2014.986185

Da Silva, J. F., Guglielmo, L. G. A., \& Bishop, D. (2010). Relationship between different measures of aerobic fitness and repeated-sprint ability in elite soccer players. Journal of Strength and Conditioning Research, 24(8), 2115-2121. doi:10.1519/JSC.0b013e3181e34794

Delextrat, A., Gregory, J., \& Cohen, D. (2010). The use of the functional H:Q ratio to assess fatigue in soccer. International Journal of Sports Medicine, 31(3), 192-197. doi:10.1055/s-0029-1243642

Fanchini, M., Schena, F., Castagna, C., Petruolo, A., Combi, F., McCall, A., \& Impellizzeri, M. (2015). External responsiveness of the Yo-Yo IR test level 1 in high-level male soccer players. International Journal of Sports Medicine, 36(9), 735-741. doi:10.1055/s-0035-1547223

Ferrari Bravo, D., Impellizzeri, F. M., Rampinini, E., Castagna, C., Bishop, D., \& Wisloff, U. (2008). Sprint vs. interval training in football. International Journal of Sports Medicine, 29(8), 668-674. doi:10.1055/s-2007-989371

Foster, C., Florhaug, J. A., Franklin, J., Gottschall, L., Hrovatin, L. A., Parker, S., ... Dodge, C. (2001). A new approach to monitoring exercise training. Journal of Strength and Conditioning Research, 15 (1), 109-115.

Girard, O., Mendez-Villanueva, A., \& Bishop, D. (2011). Repeated-sprint ability - part I: Factors contributing to fatigue. Sports Medicine (Auckland, N.Z.), 41(8), 673-694. doi:10.2165/ 11590550-000000000-00000

Hader, K., Mendez-Villanueva, A., Ahmaidi, S., Williams, B. K., \& Buchheit, M. (2014). Changes of direction during high-intensity intermittent runs: Neuromuscular and metabolic responses. $B M C$ Sports Science, Medicine and Rehabilitation, 6(1), 2-13. doi:10.1186/2052-1847-6-2

Impellizzeri, F., Marcora, S., Castagna, C., Reilly, T., Sassi, A., laia, F., \& Rampinini, E. (2006). Physiological and performance effects of generic versus specific aerobic training in soccer players. International Journal of Sports Medicine, 27(6), 483-492. doi:10.1055/s-2005-865839

Impellizzeri, F. M., Rampinini, E., \& Marcora, S. M. (2007). Physiological assessment of aerobic training in soccer. Journal of Sports Sciences, 23(6), 583-592. doi:10.1080/02640410400021278 
Ingebrigtsen, J., Brochmann, M., Castagna, C., Bradley, P., Ade, J., Krustrup, P., \& Holtermann, A. (2014). Relationship between field performance tests in high level soccer players. Journal of Strength and Conditioning Research, 28(4), 942-949. doi:10.1519/JSC.0b013e3182a1f861

Kaplan, T. (2010). Examination of repeated sprinting ability and fatigue index of soccer players according to their positions. Journal of Strength and Conditioning Research /National Strength \& Conditioning Association, 24(6), 1495-1501. doi:10.1519/JSC.0b013e3181d8e8ed

Kindermann, W., \& Meyer, T. (2003). Doubtful validity of the Yo-Yo intermittent recovery test. Medicine and Science in Sports and Exercise, 35(12), 2119; author reply 2120. 10.1249/01. MSS.0000099083.41147.5B

Krustrup, P., Mohr, M., Amstrup, T., Rysgaard, T., Johansen, J., Steensberg, A., .. Bangsbo, J. (2003). The yo-yo intermittent recovery test: Physiological response, reliability, and validity. Medicine and Science in Sports and Exercise, 35(4), 697-705. doi:10.1249/01.MSS.0000058441.94520.32

Magalhães, J., Rebelo, A., Oliveira, E., Silva, J. R., Marques, F., \& Ascensão, A. (2010). Impact of Loughborough Intermittent Shuttle Test versus soccer match on physiological, biochemical and neuromuscular parameters. European Journal of Applied Physiology, 108(1), 39-48. doi:10.1007/ s00421-009-1161-z

Manzi, V., Impellizzeri, F., \& Castagna, C. (2014). Aerobic fitness ecological validity in elite soccer players: A metabolic power approach. Journal of Strength and Conditioning Research, 28(4), 914919. doi:10.1519/JSC.0000000000000239

Marcora, S. M., \& Staiano, W. (2010). The limit to exercise tolerance in humans: Mind over muscle? European Journal of Applied Physiology, 109(4), 763-770. doi:10.1007/s00421-010-1418-6

Mendez-Villanueva, A., \& Buchheit, M. (2013). Football-specific fitness testing: Adding value or confirming the evidence? Journal of Sports Sciences, 31(13), 1503-1508. doi:10.1080/ 02640414.2013 .823231

Mohr, M., \& Krustrup, P. (2014). Yo-Yo intermittent recovery test performances within an entire football league during a full season. Journal of Sports Sciences, 32(4), 315-327. doi:10.1080/ 02640414.2013 .824598

Mohr, M., Krustrup, P., \& Bangsbo, J. (2005). Fatigue in soccer: A brief review. Journal of Sports Sciences, 23(6), 593-599. doi:10.1080/02640410400021286

Nicholas, C. W., Nuttall, F. E., \& Williams, C. (2000). The Loughborough Intermittent Shuttle Test: A field test that simulates the activity pattern of soccer. Journal of Sports Sciences, 18(2), 97-104. doi:10.1080/026404100365162

Padulo, J., Tabben, M., Ardigò, L. P., Ionel, M., Popa, C., Gevat, C., ... Dello lacono, A. (2015). Repeated sprint ability related to recovery time in young soccer players. Research in Sports Medicine, 23(4), 412-423. doi:10.1080/15438627.2015.1076419

Paul, D. J., Bradley, P. S., \& Nassis, G. P. (2015). Factors affecting match running performance of elite soccer players: Shedding some light on the complexity. International Journal of Sports Physiology and Performance, 10(4), 516-519. doi:10.1123/IJSPP.2015-0029

Sarmento, H., Marcelino, R., Anguera, M. T., Campaniço, J., Matos, N., \& Leitão, J. C. (2014). Match analysis in football: A systematic review. Journal of Sports Sciences, 32(20), 1831-1843. doi:10.1080/02640414.2014.898852

Small, K., McNaughton, L. R., Greig, M., Lohkamp, M., \& Lovell, R. (2009). Soccer fatigue, sprinting and hamstring injury risk. International Journal of Sports Medicine, 30(8), 573-578. doi:10.1055/s0029-1202822

Spencer, M., Bishop, D., Dawson, B., \& Goodman, C. (2005). Physiological and metabolic responses of repeated-sprint activities: Specificto field-based team sports. Sports Medicine (Auckland, N.Z.), 35(12), 1025-1044.

Teixeira, A. S., Da Silva, J. F., Carminatti, L. J., Dittrich, N., Castagna, C., \& Guglielmo, L. G. A. (2014). Reliability and validity of the Carminatti's test for aerobic fitness in youth soccer players. Journal of Strength and Conditioning Research, 28(11), 3264-3273. doi:10.1519/JSC.0000000000000534

Thompson, D., Nicholas, C. W., \& Williams, C. (1999). Muscular soreness following prolonged intermittent high-intensity shuttle running. Journal of Sports Sciences, 17(5), 387-395. doi:10.1080/026404199365902 